Check for updates

Cite this: RSC Adv., 2017, 7, 49273

\title{
Synthesis and $\mathrm{NO}_{2}$ gas-sensing properties of coral- like indium oxide via a facile solvothermal method
}

Received 24th August 2017

Accepted 23rd September 2017

DOI: $10.1039 / \mathrm{c} 7 \mathrm{ra0} 0397 \mathrm{~g}$

rsc.li/rsc-advances

\author{
Haijiao Zhang, ${ }^{a}$ Xiumei Xu, (D) *ac Yongsheng Zhu, (D) ab Keyan Bao, ${ }^{a}$ Zhiwen Lu, ${ }^{a}$ \\ Peng Sun, ${ }^{\mathrm{b}}$ Yanfeng Sun ${ }^{\mathrm{b}}$ and Geyu Lu*b
}

In this work, coral-like indium oxide was synthesized via an environmentally friendly one-step solvothermal method. The as-synthesized samples were characterized using X-ray powder diffraction (XRD), field emission scanning electron microscopy (FESEM), and transmission electron microscopy (TEM). The results indicate that the synthesized indium oxide nanorods were formed of nanoparticles. Moreover, the gas sensing properties of the coral-like products were investigated, and they exhibited high response and good selectivity to $\mathrm{NO}_{2}$

\section{Introduction}

In recent years, with the acceleration of global industrialization and the increase of automobile ownership, more and more toxic, harmful, flammable and explosive gases have been discharged into the atmosphere. This threatens human life and the security of property, so gas sensors are urgently needed to monitor these gases in real time. ${ }^{\mathbf{1 , 2}}$ There are various kinds of gas sensor, such as catalytic combustion type, photoionization, absorption spectrum infrared, solid electrolyte, and ultrasonic gas detectors. These detectors have the advantages of high resolution, wide detection range and long service life, but large and medium-sized instruments must be used which are demanding to the environment and relatively expensive. Sensors with real-time monitoring, portability, and agility have become the target of researchers. Due to their high sensitivity, quick response, small structure and easy integration, semiconductor sensors have become the focus of research in recent years. $^{3}$ We mainly research semiconductor oxide gas sensors based on metal oxide semiconductors, such as $\mathrm{SnO}_{2},{ }^{4-6} \mathrm{ZnO},{ }^{7,8}$ $\mathrm{WO}_{3},{ }^{9,10} \mathrm{Fe}_{2} \mathrm{O}_{3},{ }^{11,12} \mathrm{In}_{2} \mathrm{O}_{3},{ }^{13,14} \mathrm{CuO},{ }^{15,16}$ and $\mathrm{NiO} .{ }^{17}$

The gas sensing properties of materials are not only dependent on the composition of diverse elements, but also the relationship with surface morphologies, architecture, particle size and shape. Various nanostructures have been successfully prepared by different methods, such as sputtering, evaporation-condensation, high-energy mechanical ball milling, vapor deposition, coprecipitation, sol-gel, and solid phase reaction

${ }^{a}$ College of Physics and Electronic Engineering, College of Chemistry and Pharmaceutical Engineering, Nanyang Normal University, Nanyang 473061, China

${ }^{b}$ State Key Laboratory on Integrated Optoelectronics, College of Electronic Science and Engineering, Jilin University, Changchun 130012, China

${ }^{c}$ Collaborative Innovation Centre of Chemistry for Life Sciences, School of Chemistry and Chemical Engineering, Nanjing University, 163 Xianlin Ave, 210023, Nanjing, China methods. Now, more and more researchers are paying attention to one-dimensional materials because they have typical characteristics of nanoparticles (quantum size effect, small-size effect and surface effect), and unique thermal stability, electron transfer properties, photoconductivity, mechanical properties, optical properties, field emission effect, etc. Onedimensional materials have a variety of morphologies, including nanobelts, nanocables, nanodendrites, nanorods, nanotubes and multilevel structured nanofibers.

From the perspective of environmental protection and economic benefits, we hope that nanostructures can be prepared by moderate and low cost methods. As a very important wide-band-gap n-type semiconductor, indium oxide has been investigated for its gas sensitivity properties ${ }^{\mathbf{1 8}}$ for $\mathrm{CO},{ }^{19,20}$ $\mathrm{H}_{2},{ }^{21}$ VOCs, ${ }^{22} \mathrm{O}_{3}, \mathrm{Cl}_{2}$, and $\mathrm{NO}_{2} \cdot{ }^{23,24}$ In this paper, we report a facile method to prepare coral-like $\mathrm{In}_{2} \mathrm{O}_{3}$ by a solvothermal process without using any templates. The as-obtained coral-like $\mathrm{In}_{2} \mathrm{O}_{3}$ exhibited excellent gas sensitivity properties for $\mathrm{NO}_{2}$, and has potential application value for $\mathrm{NO}_{2}$ detection in an atmospheric environment.

\section{Experimental}

\subsection{Synthesis and characterization of coral-like $\operatorname{In}_{2} \mathrm{O}_{3}$}

All the reagents were used without any further purification. In a typical synthesis, $0.3536 \mathrm{~g}(1.2 \mathrm{mmol})$ of $\mathrm{InCl}_{3} \cdot 4 \mathrm{H}_{2} \mathrm{O}$ was dissolved in $36 \mathrm{~mL}$ of ethanol, then $0.5 \mathrm{~g}(1.8 \mathrm{mmol})$ sodium dodecyl sulfonate and $0.4 \mathrm{~g}(6.7 \mathrm{mmol})$ urea were added into the transparent solution. After being stirred and subjected to ultrasound for $4 \mathrm{~h}$, the formed micro-emulsion was transferred to a Teflon-lined stainless steel reaction kettle, sealed tightly, and maintained at $120{ }^{\circ} \mathrm{C}$ for $12 \mathrm{~h}$. After the reaction kettle was cooled to room temperature naturally, the precipitate was washed with ethanol six times and then dried at $80{ }^{\circ} \mathrm{C}$ for $12 \mathrm{~h}$. The precipitate was loaded into a porcelain boat which was 
placed in a muffle furnace. The furnace was slowly heated to a set temperature at a rate of $2{ }^{\circ} \mathrm{C} \mathrm{min}^{-1}$ and then kept at that temperature for $2 \mathrm{~h}$. After the furnace was cooled to room temperature, the faint yellow reaction products were collected.

$\mathrm{X}$-ray power diffraction (XRD) analysis was conducted on a Rigaku D/max-2500 X-ray diffractometer with $\mathrm{Cu} \mathrm{K} \alpha_{1}$ radiation in the range of $20-70^{\circ}(2 \theta)$ at a scanning rate of $12^{\circ} \mathrm{min}^{-1}$. The specific surface area was estimated using the BrunauerEmmett-Teller (BET) equation based on the nitrogen adsorption isotherm obtained with a Micromeritics Gemini VII apparatus (Surface Area and Porosity System). The samples were degassed under vacuum at $200{ }^{\circ} \mathrm{C}$ for $4 \mathrm{~h}$ prior to the measurements. The pore size distribution was determined with the Barrett-Joyner-Halenda (BJH) method applied to the desorption branch of the adsorption-desorption isotherm. Field emission scanning electron microscopy (FESEM) images were recorded on a JEOL JSM-7500F microscope operating at 15 $\mathrm{kV}$. Transmission electron microscopy (TEM), selected-area electron diffraction (SAED), and high-resolution transmission electron microscopy (HRTEM) measurements were obtained on a JEOL JEM-2100 microscope operated at $200 \mathrm{kV}$.

\subsection{Fabrication and measurement of the sensor}

The specific fabrication steps for the gas sensors are as follows: the faint yellow reaction product powders were mixed with ethanol to make a paste, which was coated onto an alumina tube to form a thin film. A pair of gold electrodes were installed at each end of the ceramic tube before it was coated with the paste; each electrode was connected with two Pt-wires. A Ni-Cr heating wire was inserted into the tube to form an indirectlyheated gas sensor. The structure of the sensor is shown in Fig. 1.

The gas-sensing properties of the samples were determined under laboratory conditions $\left(50 \% \pm 10 \% \mathrm{RH}, 23 \pm 1{ }^{\circ} \mathrm{C}\right)$. The measurement was processed by a static process in a test chamber. A given amount of the tested gas was injected into the test chamber, and the sensor was put into the chamber for the

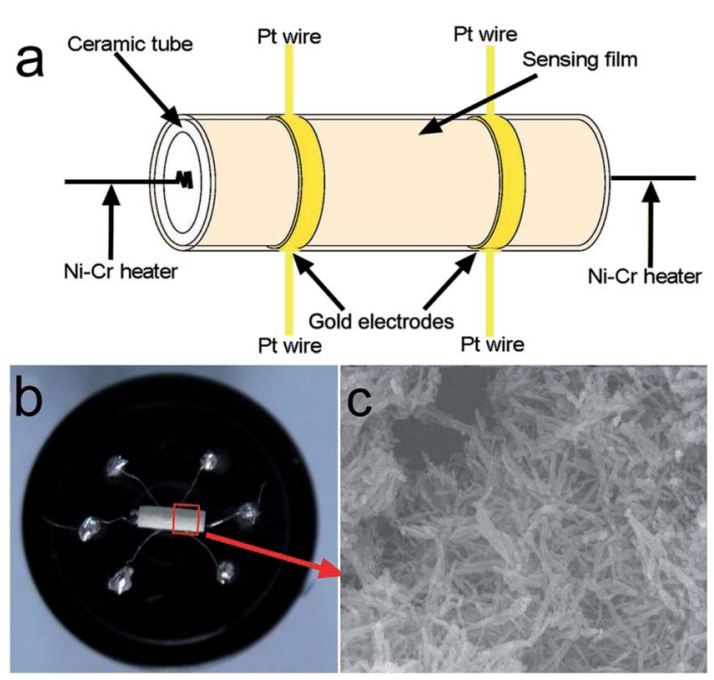

Fig. 1 (a) Schematic image of the $\ln _{2} \mathrm{O}_{3}$ sensor, (b) photograph and (c) SEM image of the $\ln _{2} \mathrm{O}_{3}$ sensor. measurement of the sensing performance. Then the calculated amount of the target gas was injected into the chamber. When the response reached a constant value, the upper cover of the test chamber was removed and the sensor began to recover in air. The response of the sensor was defined as $S=R_{\mathrm{g}} / R_{\mathrm{a}}$ for oxidizing gas or $R_{\mathrm{a}} / R_{\mathrm{g}}$ for reducing gas, where $R_{\mathrm{a}}$ and $R_{\mathrm{g}}$ are the resistances of the sensor in the air and target gas, respectively. The response and recovery times are defined as the time taken by the sensor to achieve $90 \%$ of the total resistance change in the case of adsorption and desorption, respectively.

\section{Results and discussion}

\subsection{Structural and morphological characteristics of the obtained $\operatorname{In}_{2} \mathrm{O}_{3}$}

The TG-DSC method was executed to investigate the thermal behavior of the precursors in the temperature range $30-800{ }^{\circ} \mathrm{C}$ with a rate of $10{ }^{\circ} \mathrm{C} \mathrm{min}^{-1}$ and their calcination temperatures were concluded from this method, as shown in Fig. 2 . On the TG curve, the first weight loss of $0.56 \%$ between $30{ }^{\circ} \mathrm{C}$ and $140{ }^{\circ} \mathrm{C}$ (endothermic DSC peak at $98{ }^{\circ} \mathrm{C}$ ) corresponds to the removal of water weakly adsorbed to the surface of the sample. The second weight loss step occurring between $140{ }^{\circ} \mathrm{C}$ and $550{ }^{\circ} \mathrm{C}$ (the

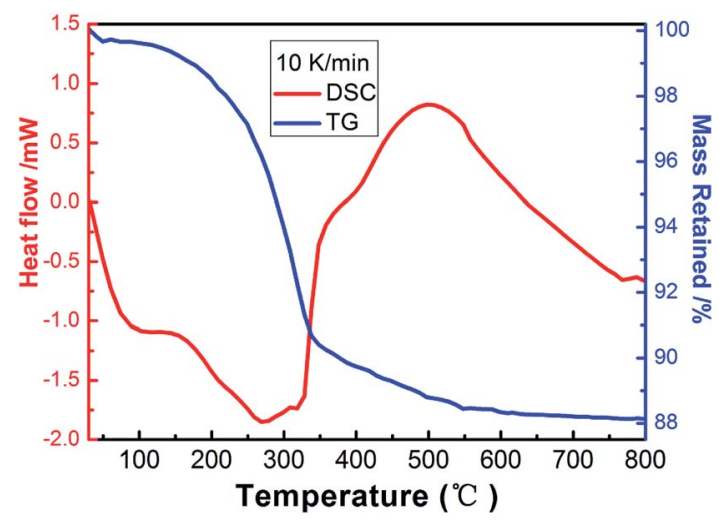

Fig. 2 Thermogravimetric (TG) and differential scanning calorimetric (DSC) analysis curves of the as-prepared sample.

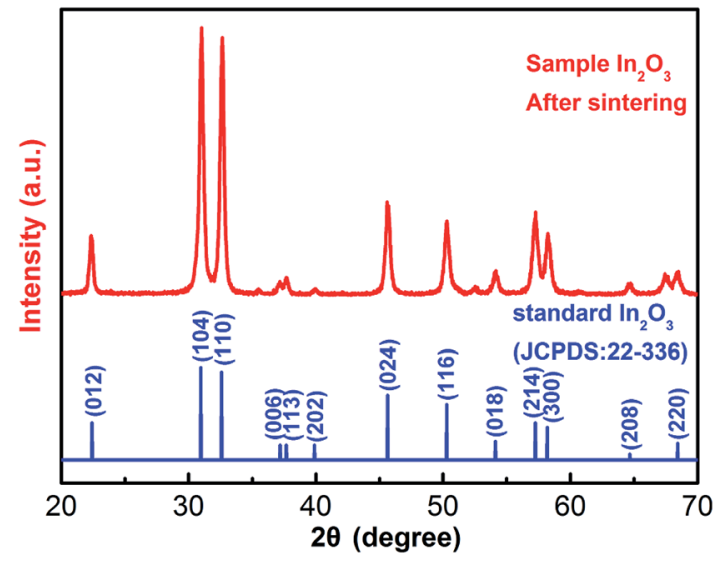

Fig. 3 X-ray diffraction patterns of the as-prepared sample of $\ln _{2} \mathrm{O}_{3}$. 

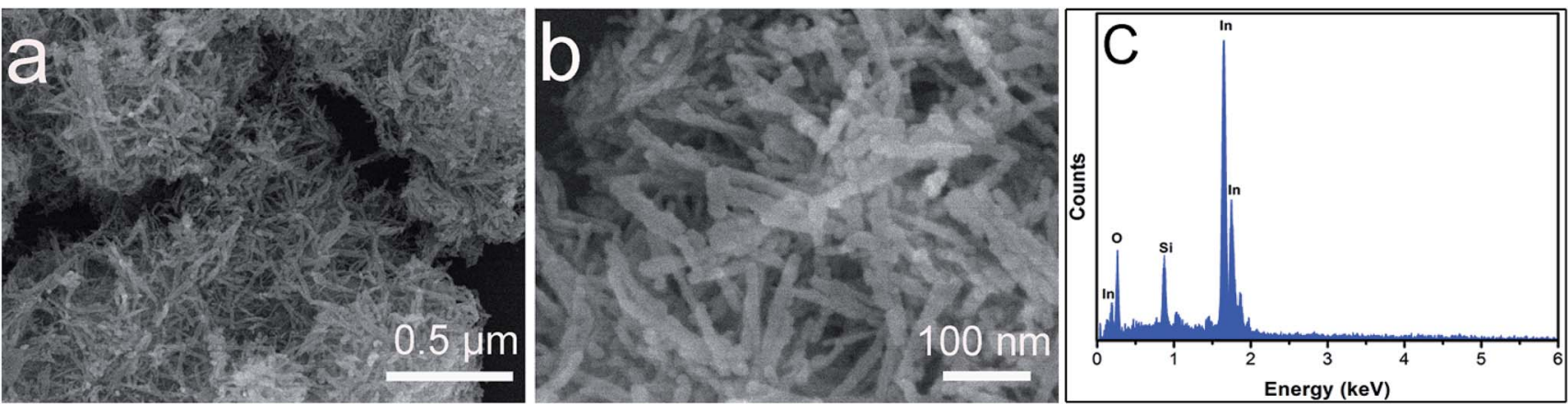

Fig. 4 FESEM images ( $a$ and b) of the as-synthesized $\ln _{2} \mathrm{O}_{3}$. The EDX pattern (c) of the coral- like $\ln _{2} \mathrm{O}_{3}$.

endothermic DSC peak at $270{ }^{\circ} \mathrm{C}$ and predominantly exothermic DSC peak at around $500{ }^{\circ} \mathrm{C}$ ) was assigned to the oxidative decomposition of the precursors leading to the formation of $\operatorname{In}_{2} \mathrm{O}_{3}$. The slight weak weight loss that occurs above $550{ }^{\circ} \mathrm{C}$ can be ascribed to the pyrolysis of organics adsorbed on the surface of the sample. After $550{ }^{\circ} \mathrm{C}$, the weight loss does not change significantly, and the weight tends to be stable. Thus, the obtained sample was chosen to be sintered at $550{ }^{\circ} \mathrm{C}$.

Fig. 3 shows the X-ray powder diffraction (XRD) pattern of the as-synthesized $\operatorname{In}_{2} \mathrm{O}_{3}$ architecture. All of the diffraction peaks can be indexed to a pure rhombohedral structure of $\operatorname{In}_{2} \mathrm{O}_{3}$ according to JCPDS card no. 22-336, with the space group $R \overline{3} c$ (no. 167) and lattice parameters of $a=5.48 \AA$ and $c=14.5 \AA$. The morphology of the samples was investigated by field emission scanning electron microscopy (FESEM).

Fig. 4 shows typical FESEM images of the sample of $\operatorname{In}_{2} \mathrm{O}_{3}$ at different magnification. The low magnification SEM image shown in Fig. 4a reveals that the nanorods with a rough surface were $100 \mathrm{~nm}$ in length. No other morphologies could be detected, indicating a high yield of these structures. Fig. $4 \mathrm{~b}$ shows the morphology of an individual rod in a highermagnification FESEM image, indicating that such structures are constructed from nanoparticles. The EDX pattern of the product, shown in Fig. $4 \mathrm{c}$, indicates that the prepared $\operatorname{In}_{2} \mathrm{O}_{3}$ is composed of only three elements: In, O, and $\mathrm{Si}$ ( $\mathrm{Si}$ from the $\mathrm{Si}$ substrate used for measurement).

Further detailed structural analysis of the individual nanorods was carried out using TEM. Fig. 5 presents typical TEM images of the as-synthesized $\operatorname{In}_{2} \mathrm{O}_{3}$ nanorods, in accordance
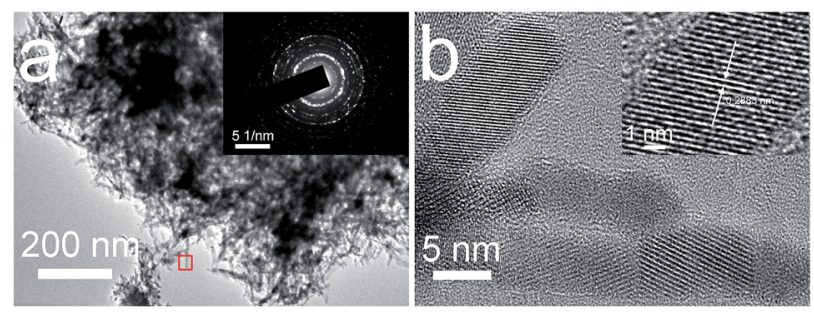

Fig. 5 Typical TEM images ( $a$ and $b$ ) of the $\ln _{2} \mathrm{O}_{3}$ nanostructures. The corresponding SAED pattern (inset a). HRTEM image (inset b) taken from (a) and (b). with the SEM images. As seen from the image, the thickness of the $\mathrm{In}_{2} \mathrm{O}_{3}$ nanorods was about $5-10 \mathrm{~nm}$. The selected-area electron diffraction (SAED) pattern of an individual $\mathrm{In}_{2} \mathrm{O}_{3}$ nanorod (inset of Fig. 5a) confirms that the as-synthesized products were polycrystalline in structure. The high-resolution transmission electron microscopy (HRTEM) image (inset of Fig. 5b) shows a fringe distance of $0.288 \mathrm{~nm}$, corresponding to the lattice distances of the (104) plane of hexagonal $\operatorname{In}_{2} \mathrm{O}_{3}$.

To further obtain information about the coral-like $\operatorname{In}_{2} \mathrm{O}_{3}$, nitrogen adsorption and desorption measurements were performed at $77 \mathrm{~K}$. The representative $\mathrm{N}_{2}$ adsorption and desorption isotherm and the corresponding $\mathrm{BJH}$ pore size distribution plot (inset of Fig. 6) of the hierarchical microspheres are shown in Fig. 6. The BET surface area of the product was calculated to be $86.4 \mathrm{~m}^{2} \mathrm{~g}^{-1}$ with the Brunauer-Emmett-Teller (BET) method. The adsorption-desorption isotherms are typical type IV with a hysteresis loop according to the IUPAC classification, indicating that the powders contain disordered mesopores. Pore size distribution curves were calculated from the desorption branch of the nitrogen isotherm by the $\mathrm{BJH}$ method using the Halsey equation.

To investigate the role of solvent in the formation of $\operatorname{In}_{2} \mathrm{O}_{3}$, controlled experiments of the process with different solvents were carried out by keeping other experimental conditions constant. When the experiments were performed with ethanol

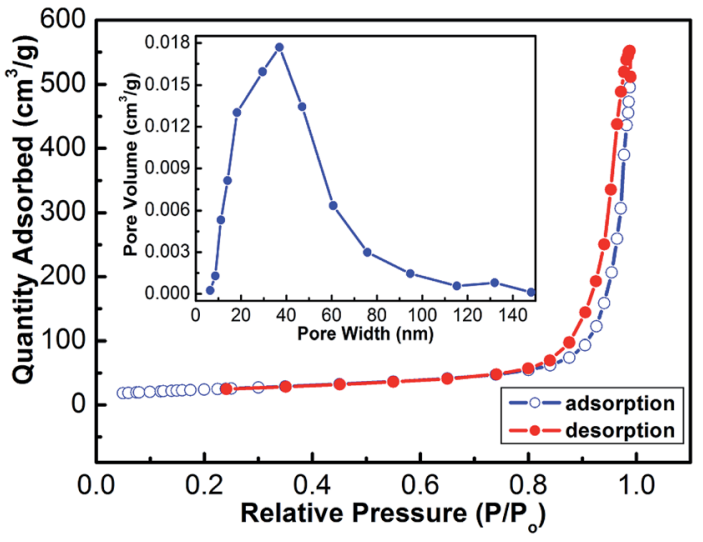

Fig. 6 Typical $\mathrm{N}_{2}$ adsorption-desorption isotherms of the $\ln _{2} \mathrm{O}_{3}$ nanorods. The inset is the corresponding pore size distribution curve. 

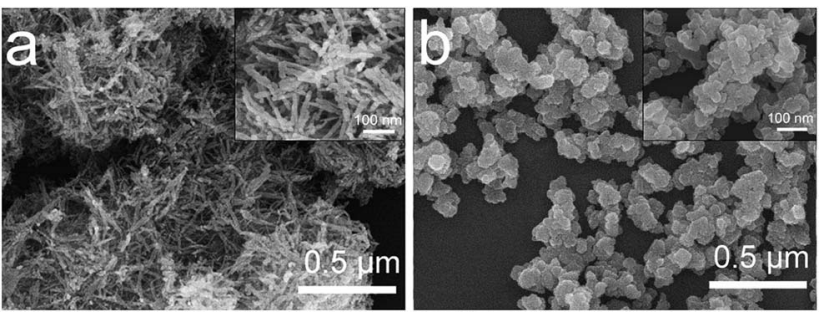

Fig. 7 FESEM images of $\ln _{2} \mathrm{O}_{3}$ synthesized with different solvents: (a) ethanol and (b) ethylene glycol.

and ethylene glycol, coral-like nanostructures (Fig. 7a) and irregular microspheres (Fig. 7b) were obtained, respectively. The insets in (a) and (b) are the corresponding highmagnification FESEM images. Ethanol and ethylene glycol were used not only as solvents but also as surfactants, which could greatly affect the morphology and microstructure of the products. $^{25,26}$ They can regulate the nucleation kinetics and growth of the products and efficiently control the morphology and structure of the final products. ${ }^{27}$

\subsection{Gas-sensing properties for $\mathbf{N O}_{2}$}

The gas sensing properties of the sensors based on the nanostructures obtained with ethanol and ethylene glycol (abbreviated to $S_{1}$ and $S_{2}$ ) were investigated. As is well known, the response of oxide semiconductors is highly influenced by the operating temperature. ${ }^{28}$

In order to determine the optimum operating temperature, the responses of the sensors to $1 \mathrm{ppm}$ of $\mathrm{NO}_{2}$ were tested at different temperatures from $50{ }^{\circ} \mathrm{C}$ to $210{ }^{\circ} \mathrm{C}$. The relationship between the gas response and operating temperature is shown in Fig. 8. Obviously, sensor $S_{1}$ showed a better gas response to $1 \mathrm{ppm}$ of $\mathrm{NO}_{2}$ than sensor $S_{2}$. The optimum operating temperatures of sensor $S_{1}$ and sensor $S_{2}$ are $130{ }^{\circ} \mathrm{C}$ and $145{ }^{\circ} \mathrm{C}$, which were applied in the following investigations for sensor $S_{1}$ and sensor $S_{2}$. It can be obviously seen that the response of each

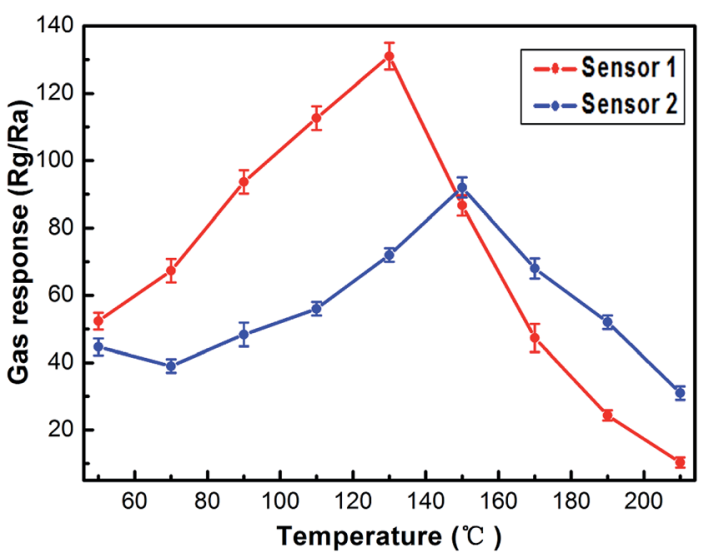

Fig. 8 Response of the sensors to $1 \mathrm{ppm}$ of $\mathrm{NO}_{2}$ as a function of operating temperature.
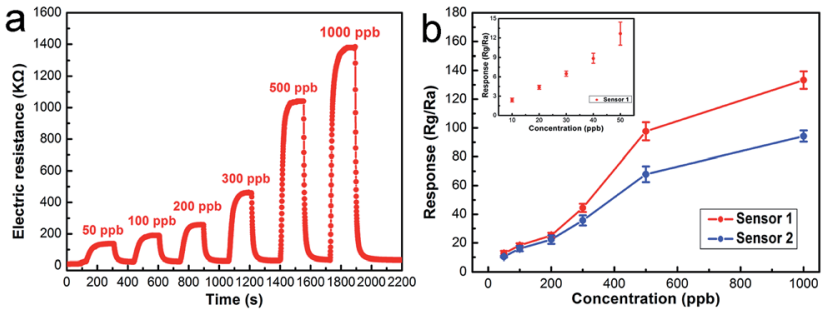

Fig. 9 (a) The response transients of $S_{1}$ to different $\mathrm{NO}_{2}$ concentrations. (b) Gas response of the sensors as a function of $\mathrm{NO}_{2}$ concentration (inset of (b) is the gas response of $S_{1}$ from $10 \mathrm{ppb}$ to $50 \mathrm{ppb}$ ).

sensor increases in the initial stage and decreases on further increasing the temperature.

Fig. 9a displays the real-time response curves of coral-like $\mathrm{In}_{2} \mathrm{O}_{3}\left(S_{1}\right)$ to $\mathrm{NO}_{2}$ with concentrations varying from $50 \mathrm{ppb}$ to $1 \mathrm{ppm}$. It can be seen that the gas response increased with increasing $\mathrm{NO}_{2}$ concentration. The resistances increased upon exposure to $\mathrm{NO}_{2}$, which is consistent with the gas sensing behavior of n-type oxide semiconductors. The functional relationship between the response of the sensor and the concentration of $\mathrm{NO}_{2}$ is shown in Fig. 9b. The detection limit of $S_{1}$ is 10 $\mathrm{ppb}$, and with increasing $\mathrm{NO}_{2}$ concentration $S_{1}$ exhibited a superior response compared to $S_{2}$. The coral-like $\operatorname{In}_{2} \mathrm{O}_{3}$ nanostructure sensor shows an acceptable response from the view of practical application. When the sensor was exposed to $10 \mathrm{ppb} \mathrm{NO}_{2}$, the response value was 2.41 . The response value was about $4.35,6.5,8.9,13.5,18.2,24.5,43.8,98$ and 132 to 20 , $30,40,50,100,200,300,500$ and $1000 \mathrm{ppb} \mathrm{NO}_{2}$, respectively.

The response transient curve of the coral-like $\mathrm{In}_{2} \mathrm{O}_{3}$ nanostructure sensor to $1 \mathrm{ppm} \mathrm{NO}_{2}$ was measured at $130{ }^{\circ} \mathrm{C}$ (Fig. 10), and the response time and recovery time were about $40 \mathrm{~s}$ and $22 \mathrm{~s}$, respectively. The six reversible cycles of the response curve indicate a stable and repeatable response characteristic, as shown in the inset of Fig. 10.

A comparison between the sensing performances of the sensor and those in literature reports ${ }^{29-35}$ is summarized in Table 1. From the table, it can be observed that the sensor based on the coral-like $\operatorname{In}_{2} \mathrm{O}_{3}$ nanostructures has a correspondingly

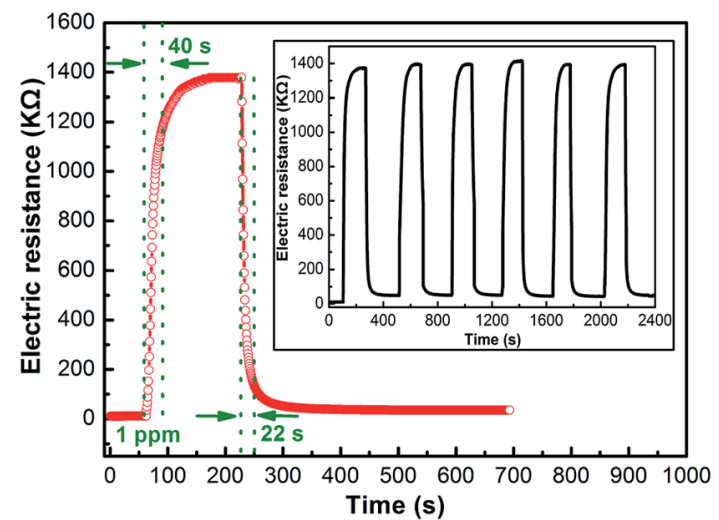

Fig. 10 Response transient curve and (inset) the repeated response transient curves to $1 \mathrm{ppm} \mathrm{NO}$ for the sensor at $130{ }^{\circ} \mathrm{C}$. 
Table 1 Gas responses to $\mathrm{NO}_{2}$ in the present study and those reported in the literature $\mathrm{e}^{29-35}$

\begin{tabular}{|c|c|c|c|c|}
\hline Sensing materials & $\begin{array}{l}\mathrm{NO}_{2} \text { concentration } \\
(\mathrm{ppm})\end{array}$ & $\begin{array}{l}\text { Working temperature } \\
\left({ }^{\circ} \mathrm{C}\right)\end{array}$ & Sensor response & Reference \\
\hline $\mathrm{In}_{2} \mathrm{O}_{3}$ nanosheets & 5 & 250 & 42 & 29 \\
\hline $\mathrm{SnO}_{2}$ nanowires & 1 & 200 & 20 & 31 \\
\hline ZnO nanoflowers & 1 & 174 & 14 & 32 \\
\hline ZnO nanorods & 1 & 150 & 6 & 33 \\
\hline Coral-like $\operatorname{In}_{2} \mathrm{O}_{3}$ & 0.5 & 130 & 98 & Present work \\
\hline
\end{tabular}

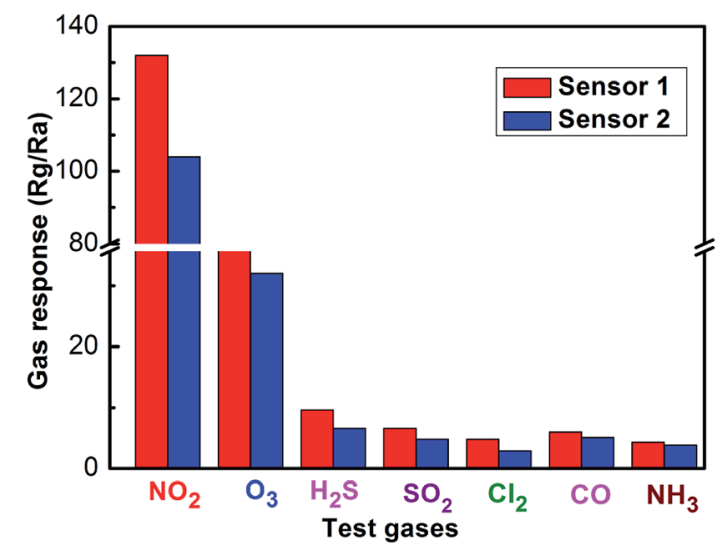

Fig. 11 Cross-responses of the sensor to various test gases at $130{ }^{\circ} \mathrm{C}$.

higher gas response and lower working temperature. Fig. 11 shows the response of the sensors using coral-like $\operatorname{In}_{2} \mathrm{O}_{3}$ to various target gases. All of the gases were tested at an operating temperature of $130{ }^{\circ} \mathrm{C}$ with a concentration of $1 \mathrm{ppm}$. It can be

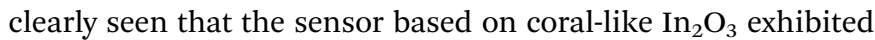
the highest response to $\mathrm{NO}_{2}$ and negligible responses to other gases. Furthermore, good long-term stability was also a key parameter determining whether gas sensors could detect accurately in practical use or not. As shown in Fig. 12, there was no obvious variation among the values of resistance in air at $130{ }^{\circ} \mathrm{C}$ and their corresponding gas responses to $1 \mathrm{ppm} \mathrm{NO}_{2}$ in the 30 days of testing, which meant that the coral-like $\operatorname{In}_{2} \mathrm{O}_{3}$ gas sensor had reliable and good long-term stability.

The $\mathrm{NO}_{2}$ sensing mechanism can be described by the following equations: ${ }^{36-38}$

$$
\begin{gathered}
\mathrm{NO}_{2 \text { (gas) }}+\mathrm{e}^{-} \rightarrow \mathrm{NO}_{2}^{-}{ }_{(\text {ads })} \\
\mathrm{NO}_{2 \text { (gas) }}+2 \mathrm{O}^{-}{ }_{\text {(ads) }} \rightarrow \mathrm{NO}_{2}{ }^{-}{ }_{\text {(ads) }}+\mathrm{O}_{2(\text { gas })}+\mathrm{e}^{-} \\
\mathrm{NO}_{2 \text { (gas) }}+\mathrm{O}^{-}{ }_{\text {(ads) }} \rightarrow \mathrm{NO}^{+}{ }_{(\text {ads })}+2 \mathrm{O}^{-}{ }_{\text {(ads })}
\end{gathered}
$$

Compared with sensor 2, the excellent gas sensitivity of coral-like $\operatorname{In}_{2} \mathrm{O}_{3}$ (sensor 1) can be attributed to the abundant framework of gas diffusion and chemical adsorption as well as the reaction on the surface of the indium trioxide material. ${ }^{39}$ The network of pores of the coral-like structure enables gas to

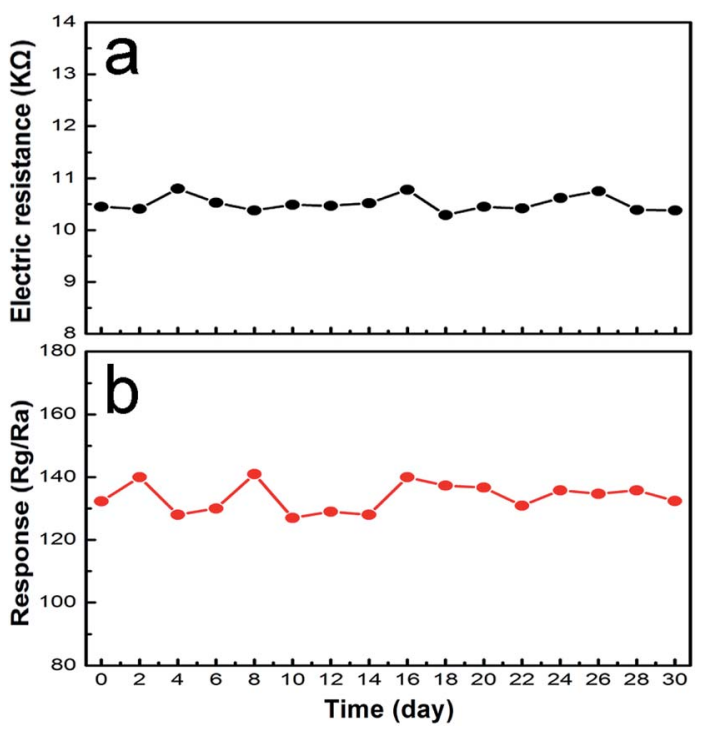

Fig. 12 (a) Resistances in air and (b) responses to $1 \mathrm{ppm} \mathrm{NO} \mathrm{N}_{2}$ of the coral-like $\ln _{2} \mathrm{O}_{3}$ sensor as a function of the days of testing at $130{ }^{\circ} \mathrm{C}$.

diffuse easily to the surface of $\operatorname{In}_{2} \mathrm{O}_{3}$. Therefore, the sensor has a high response to $\mathrm{NO}_{2}$. Thus the novel coral-like $\operatorname{In}_{2} \mathrm{O}_{3}$ can be used as a promising sensing material.

\section{Conclusion}

In summary, coral-like $\operatorname{In}_{2} \mathrm{O}_{3}$ was successfully synthesized by a solvothermal method, after calcination of the precursor at $550^{\circ} \mathrm{C}$ for $2 \mathrm{~h}$. Field emission scanning electron microscopy and transmission electron microscopy show that the coral-like $\operatorname{In}_{2} \mathrm{O}_{3}$ was composed of nanorods. The gas sensing properties of sensors based on the as-synthesized $\mathrm{In}_{2} \mathrm{O}_{3}$ towards $\mathrm{NO}_{2}$ were investigated. The sensor exhibits excellent $\mathrm{NO}_{2}$ sensing properties at $130{ }^{\circ} \mathrm{C}$. The sensor response is about 2.41 to $10 \mathrm{ppb} \mathrm{NO}_{2}$ at $130{ }^{\circ} \mathrm{C}$. The response time and recovery time were about $40 \mathrm{~s}$ and $22 \mathrm{~s}$, respectively. These results suggest that our sensor might have potential application in the fabrication of highly sensitive and low power consumption $\mathrm{NO}_{2}$ gas sensor devices.

\section{Conflicts of interest}

There are no conflicts to declare. 


\section{Acknowledgements}

This work is supported by the National Natural Science Foundation of China (61473132, 61474057, 11504131, 11504188 and 61703216), "863" High Technology Project (2013AA030902 and 2014AA06A505), school-based program of Nanyang Normal University (QN2016017 and QN2017054), Henan Province Department of Education Project (No. 17A510003 and 16HASTIT010), Henan Joint Funds of the National Natural Science Foundation of China (U1404608, U1404216, U1404505 and U1504626), and Innovation Scientists and Technicians Troop Construction Projects of Henan Province (No. C20150029).

\section{References}

1 G. B. Hamra, F. Laden, A. J. Cohen, O. Raaschou-Nielsen, M. Brauer and D. Loomis, Environ. Health Perspect., 2015, 123, 1107-1112.

2 K. Ram, M. Sarin, A. Sudheer and R. Rengarajan, Aerosol Air Qual. Res., 2012, 12, 359-370.

3 N. Yamazoe and K. Shimanoe, Sens. Actuators, B, 2009, 138, 100-107.

4 C. Xu, J. Tamaki, N. Miura and N. Yamazoe, Sens. Actuators, $B$, 1991, 3(2), 147-155.

5 M. Law, H. Kind and B. Messer, Angew. Chem., Int. Ed., 2002, 114(13), 2511-2514.

6 M. Poloju, N. Jayababu, E. Manikandan and M. V. R. Reddy, J. Mater. Chem. C, 2017, 5, 2662-2668.

7 X. F. Pan, X. J. Zhao, J. Q. Chen, A. Bermak and Z. Y. Fan, Sens. Actuators, B, 2015, 206, 764-771.

8 Y. Xia, J. Wang, J. L. Xu, X. Li, D. Xie, L. Xiang and S. Komarneni, ACS Appl. Mater. Interfaces, 2016, 8, 3545435463.

9 M. Akiyama, J. Tamaki, N. Miura and N. Yamazoe, Chemistry Letters, 1991, 20, 1611-1614.

10 S. Ashraf, C. S. Blackman, R. G. Palgrave, S. C. Naisbitt and I. P. Parkin, J. Mater. Chem., 2007, 17, 3708-3713.

11 L. P. Zhu, N. C. Bing, L. L. Wang, H. Y. Jin, G. H. Liao and L. J. Wang, Dalton Trans., 2012, 41, 2959-2965.

12 B. Zhang, J. Liu, X. B. Cui, Y. L. Wang, Y. Gao, P. Sun, F. M. Liu, K. Shimanoe, N. Yamazoe and G. Y. Lu, Sens. Actuators, B, 2016, 241, 904-914.

13 D. H. Zhang, Z. Q. Liu, C. Li, T. Tang, X. L. Liu, S. Han, B. Lei and C. W. Zhou, Nano Lett., 2004, 4, 1919-1924.

14 S. Park, G. J. Sun, H. Kheel, I. L. Wan, S. Lee, S. B. Choid and C. Lee, Sens. Actuators, B, 2016, 227, 591-599.

15 L. A. Patil and D. R. Patil, Sens. Actuators, B, 2006, 120, 316323.

16 J. P. Liu, X. T. Huang, Y. Y. Li, Z. K. Li, Q. B. Chi and G. Y. Li, Solid State Sci., 2008, 11, 1568-1576.
17 S. L. Xiong, C. Z. Yuan, X. G. Zhang and Y. T. Qian, CrystEngComm, 2011, 13, 626-632.

18 M. Liess, Thin Solid Films, 2002, 410, 183-187.

19 N. Singh, C. Yan and P. S. Lee, Sens. Actuators, B, 2010, 150, 19-24.

20 K. L. Sang, S. H. Hwang, D. Chang and S. Kim, Sens. Actuators, B, 2010, 149, 28-33.

21 A. Qurashi, T. Yamazaki, E. M. El-Maghraby and T. Kikuta, Appl. Phys. Lett., 2009, 95(15), 083124.

22 R. Q. Xing, L. Xu, J. Song, C. Y. Zhou, Q. L. Li, D. L. Liu and H. W. Song, Sci. Rep., 2015, 5, 10717.

23 P. C. Xu, Z. X. Cheng, Q. Y. Pan, J. Q. Xu, Q. Xiang, W. J. Yu and Y. L. Chu, Sens. Actuators, B, 2008, 130, 802-808.

24 F. Gu, R. Nie, D. Han and Z. Wang, Sens. Actuators, B, 2015, 219, 94-99.

25 C. M. Zhang, C. X. Li, C. Peng, R. T. Chai, S. S. Huang, D. M. Yang, Z. Y. Cheng and J. Lin, Chem.-Eur. J., 2010, 16, 5672-5680.

26 R. Jin, Y. Xu, G. Li, J. Liu and G. Chen, Int. J. Hydrogen Energy, 2013, 38(22), 9137-9144.

27 H. X. Dong, Z. H. Chen, L. X. Sun, L. Zhou, Y. J. Ling, C. Z. Yu, H. Hoe Tan, C. Jagadish and X. C. Shen, J. Phys. Chem. C, 2009, 113, 10511-10516.

28 T. M. E. Franke, T. J. Koplin and U. Simon, Small, 2006, 2, 36-50.

29 L. P. Gao, Z. X. Cheng, Q. Xiang, Y. Zhang and J. Q. Xu, Sens. Actuators, B, 2015, 208, 436-443.

30 B. J. Kim, I. G. Song and J. S. Kim, Electron. Mater. Lett., 2014, 10, 509-513.

31 S. W. Choi, S. H. Jung and S. S. Kim, J. Hazard. Mater., 2016, 665, 173-179.

32 J. Li, W. G. Zhang and J. B. Sun, Ceram. Int., 2016, 42, 98519857.

33 D. V. Ponnuvelu, B. Pullithadathil, A. K. Prasad, S. Dhara, A. Ashok, K. Mohamed, A. K. Tyagi and B. Raj, Appl. Surf. Sci., 2015, 355, 726-735.

34 T. Tesfamichael, C. Piloto, M. Arita and J. Bell, Sens. Actuators, B, 2015, 221, 393-400.

35 Z. H. Wang, M. Hu, Y. F. Wang, X. C. Liu and Y. X. Qin, J. Alloys Compd., 2016, 665, 173-179.

36 N. Yamazoe and K. Shimanoe, Sens. Actuators, B, 2010, 150, 132-140.

37 C. S. Rout, K. Ganesh, A. Govindaraj and C. N. R. Rao, Appl. Phys. A: Mater. Sci. Process., 2006, 85, 241-246.

38 N. Barsan, D. Koziej and U. Weimar, Sens. Actuators, B, 2007, 121, 18-35.

39 P. Sun, C. Wang, X. Zhou, P. F. Cheng, K. Shimanoe, G. Y. Lu and N. Yamazoe, Sens. Actuators, B, 2014, 193, 616-622. 